\title{
Structure-Activity Relationships in Pt-Functionalized Graphitic Carbon Nitride Photocatalysts
}

\author{
Diane M. Haiber $^{1 *}$ and Peter A. Crozier ${ }^{1}$ \\ 1. School for Engineering of Matter, Transport \& Energy, Arizona State University, Tempe, AZ, USA \\ *dhaiber@asu.edu
}

Graphitic carbon nitrides $\left(\mathrm{g}-\mathrm{CN}_{\mathrm{x}} \mathrm{H}_{\mathrm{y}} \mathrm{s}\right)$ offer immense potential as inexpensive photocatalysts for solar fuel generation (e.g., $\mathrm{H}_{2}$ from water) owing to their facile synthesis from a range of precursors, ability to absorb visible light, and high surface area [1]. Typically, $\mathrm{g}-\mathrm{CN}_{\mathrm{x}} \mathrm{H}_{\mathrm{y}} \mathrm{s}$ are functionalized with $\mathrm{Pt}$ via photodeposition at high loadings $\left(e . g ., \sim 1-5 \mathrm{wt} \%\right.$ ) but single-atom Pt cocatalyst can also be used for $\mathrm{H}_{2}$ evolution at much lower loadings [2]. Recent experimental and theoretical work has highlighted the importance of native $\mathrm{N}-\mathrm{H}_{2}$ defects in facilitating interfacial charge transfer to supported Pt cocatalyst [3]. Nanoscale characterization should reveal more precise structure-function relationships leading to rational design strategies for $\mathrm{Pt} / \mathrm{g}-\mathrm{CN}_{\mathrm{x}} \mathrm{H}_{\mathrm{y}}$ photocatalysts that maximize energy conversion efficiency and minimize Pt consumption.

A systematic study correlating the $\mathrm{H}_{2}$ evolution rates (HERs), bulk characterization of the $\mathrm{g}-\mathrm{CN}_{\mathrm{x}} \mathrm{H}_{\mathrm{y}}$ supports, and active site densities determined from annular dark field scanning transmission electron microscopy (ADF-STEM) was performed to understand photocatalytic activity in $\mathrm{Pt} / \mathrm{g}-\mathrm{CN}_{\mathrm{x}} \mathrm{H}_{\mathrm{y}} \mathrm{S}$ at multiple length scales. Three $\mathrm{g}-\mathrm{CN}_{\mathrm{x}} \mathrm{H}_{\mathrm{y}} \mathrm{s}$ demonstrating a range in structural condensation (based on $\mathrm{X}$ ray diffraction) were selected including a commercially-produced "Nicanite" and two urea-derived g$\mathrm{CN}_{\mathrm{x}} \mathrm{H}_{\mathrm{y}} \mathrm{s}$. Nicanite is the most structurally condensed with the smallest interplanar spacing. The ureabased $\mathrm{g}-\mathrm{CN}_{\mathrm{x}} \mathrm{H}_{\mathrm{y}} \mathrm{S}$ were synthesized by calcining urea at $550^{\circ} \mathrm{C}$ for 30 and 240 minutes to yield $\mathrm{U}_{30}-\mathrm{gCN}$ and $\mathrm{U}_{240} \mathrm{gCN}$, respectively, which show more narrowed layer stacking distances with calcination time. HERs were determined from gas chromatography of the photoreactor headspace under visible light irradiation $(\lambda>400 \mathrm{~nm})$ and in 10 vol\% aqueous triethanolamine. Pt was loaded onto each $\mathrm{g}-\mathrm{CN}_{\mathrm{x}} \mathrm{H}_{\mathrm{y}}$ via photodeposition (PD) from $\mathrm{PtCl}_{4}$ at a loading $1.6 \mathrm{wt} \%$, yielding active sites for $\mathrm{H}_{2}$ evolution.

When each support is loaded with Pt via PD, the HER of $\mathrm{U}_{240}-\mathrm{gCN}$ is $>2 \mathrm{x}$ higher than that of Nicanite or $\mathrm{U}_{30-\mathrm{gCN}}$ (Figure 1). ADF-STEM imaging of the used Pt/g- $\mathrm{CN}_{\mathrm{x}} \mathrm{H}_{\mathrm{y}} \mathrm{s}$ (Figure $2 \mathrm{a}-\mathrm{c}$, e) reveals that the Pt particle size distribution varies widely with the support structure and $\mathrm{U}_{240}-\mathrm{gCN}$ facilitates the most dispersed cocatalyst species. By normalizing the HER by the total number of active sites (i.e., the number of surface-exposed Pt atoms) estimated from the particle size distributions, different $\mathrm{g}-\mathrm{CN}_{\mathrm{x}} \mathrm{H}_{\mathrm{y}} \mathrm{s}$ ' turn over frequency (TOF) can be compared. The TOF describes the rate of $\mathrm{H}_{2}$ produced per active site and unlike the HER, is not influenced by ensemble effects. This analysis reveals the following trend in TOF: Nicanite $\left(213 \mathrm{~h}^{-1}\right)>\mathrm{U}_{240}-\mathrm{gCN}\left(146 \mathrm{~h}^{-1}\right)>\mathrm{U}_{30}-\mathrm{gCN}\left(103 \mathrm{~h}^{-1}\right)$. Alternatively, predominately singleatom $\mathrm{Pt}$ was deposited onto Nicanite following a chemical reduction (CR) approach (Figure 2d-e), achieving a low loading of $0.15 \mathrm{wt} \%$ and peak HER of $880 \mu \mathrm{mol} / \mathrm{h} / \mathrm{g}$ (Figure 1) [3]. The TOF of this photocatalyst, at $196 \mathrm{~h}^{-1}$, is similar to Nicanite prepared with PD at high loading. Ultimately, the stacking distance of the light-harvesting support was found to strongly correlate with the TOF, which we speculate originates from higher mobilities in more structurally condensed $\mathrm{g}-\mathrm{CN}_{\mathrm{x}} \mathrm{H}_{\mathrm{y}} \mathrm{s}$ meaning more photogenerated electrons may reach the surface for performing water reduction [4]. In Nicanite, the low active site densities resulting from both PD and CR appear to limit the overall HER suggesting this factor is critical to achieving high energy conversion efficiencies. Methods for evaluating photocatalytic 
activity in complex systems like $\mathrm{Pt} / \mathrm{g}-\mathrm{CN}_{\mathrm{x}} \mathrm{H}_{\mathrm{y}} \mathrm{s}$ will also be emphasized.

References:

[1] T.S. Miller et al., Phys. Chem. Chem. Phys. 19 (2017), p. 15613.

[2] X. Li et al., Adv. Mater. 28 (2016), p. 2427.

[3] V.W. Lau et al., Adv. Energy Mater. 7 (2017), p. 1062251.

[4] C. Merschjann et al., Adv. Mater. 27 (2015), p. 7993.

[5] We gratefully acknowledge the support from the DOE (DE-SC0004954), ASU's John M. Cowley

Center for High Resolution Electron Microscopy and ASU's Eyring Materials Center.

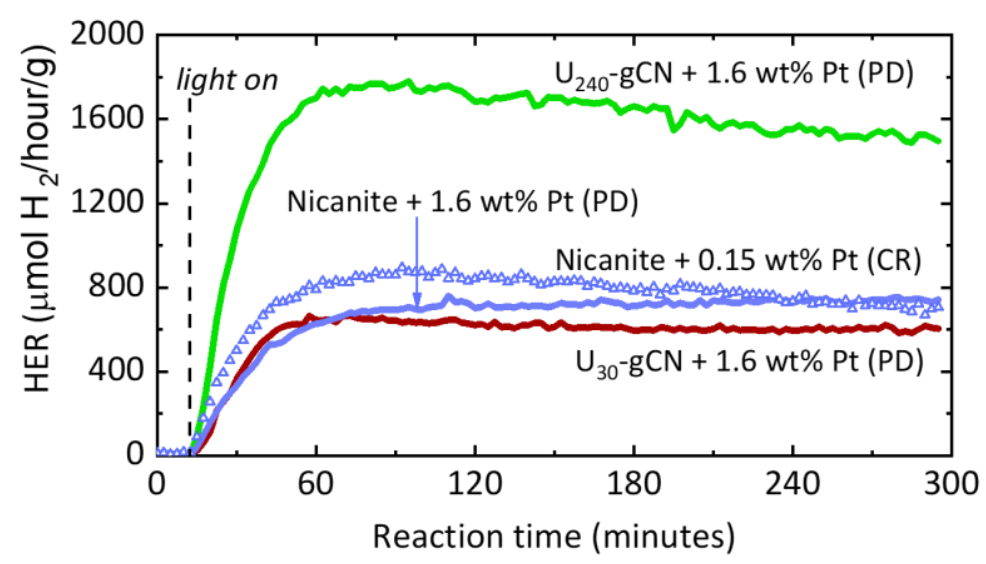

Figure 1. $\mathrm{H}_{2}$ evolution rates (HER), per mass of photocatalyst, of different $\mathrm{Pt} / \mathrm{g}-\mathrm{CN}_{\mathrm{x}} \mathrm{H}_{\mathrm{y}} \mathrm{s}$. $\mathrm{Pt}$ was loaded onto the supports either through photodeposition (PD) or chemical reduction (CR).
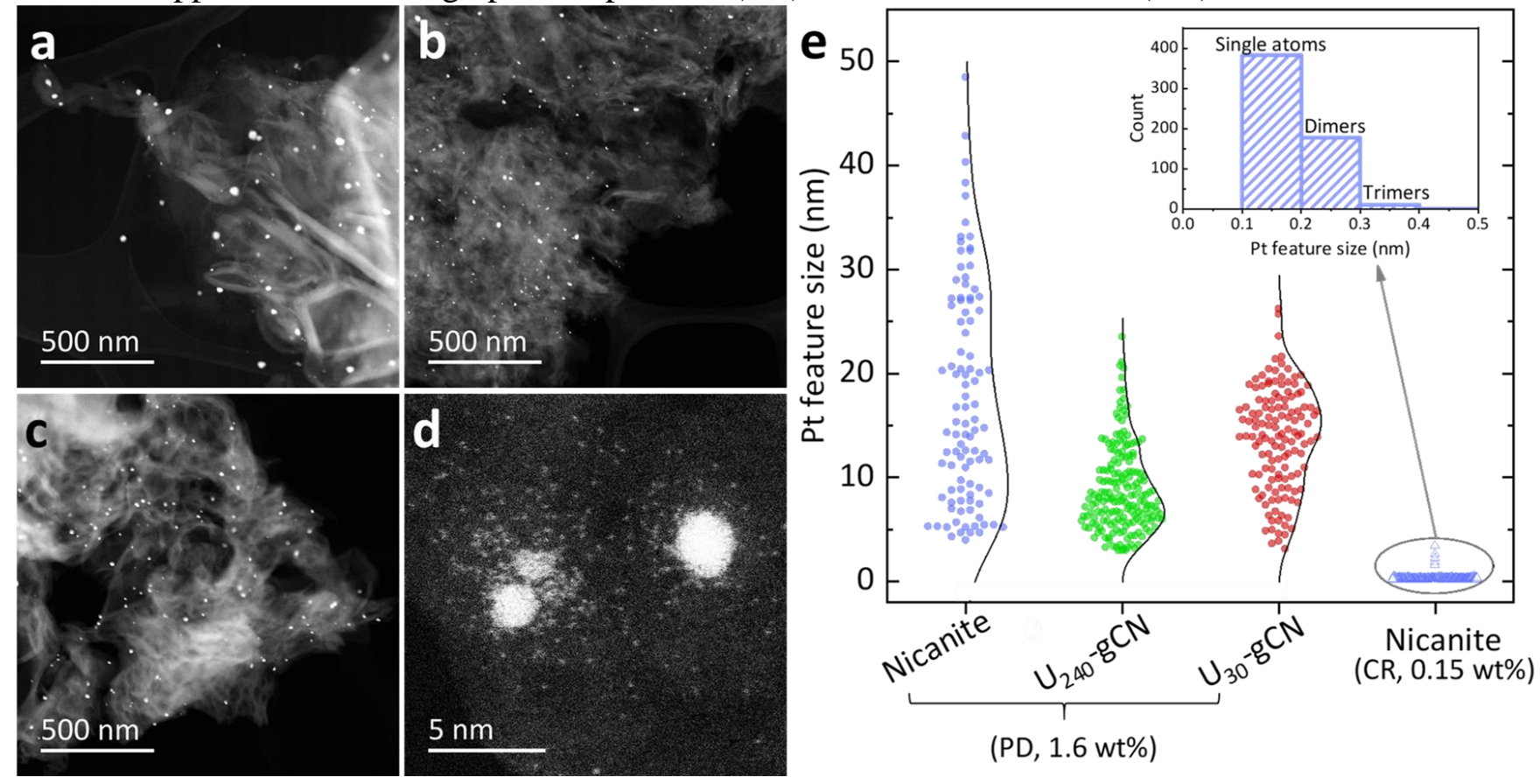

Figure 2. ADF-STEM images of photocatalysts prepared via PD at a loading of $1.6 \mathrm{wt} \%$ : (a) Nicanite, (b) $\mathrm{U}_{240}-\mathrm{gCN}$, and (c) $\mathrm{U}_{30}-\mathrm{gCN}$. (d) ADF-STEM image of Nicanite loaded with $0.15 \mathrm{wt} \% \mathrm{Pt}$ using CR. (e) Pt features size distributions and violin plots of each photocatalyst used to estimate active site densities; inset shows a more detailed histogram of Pt on Nicanite prepared with CR. 